\title{
Optimasi Siklus Kalina KCS34 Pada Pemanfaatan Sumber Air Panas (Natural Hot Spring) Sebagai Pembangkit Listrik
}

\author{
Muhammad Pramuda N.S, M. Ridwan, Iqbal Maulana \\ Jurusan Teknik Mesin, Fakultas Teknik Industri, ITENAS, Bandung \\ Email: pramudasirodz26@gmail.com
}

\begin{abstract}
ABSTRAK
Indonesia memiliki potensi panas bumi yang besar. Daerah potensi panas bumi seperti di daerah Cimanggu, Provinsi Jawa Barat umumnya memiliki sumber air panas. Sumber air panas selain dimanfaatkan untuk pariwisata, dapat pula dimanfaatkan sebagai pembangkit tenaga listrik. Temperatur sumber air panas yang relatif rendah antara $60^{\circ}-90^{\circ} \mathrm{C}$ membutuhkan teknologi khusus agar dapat dimanfaatkan sebagai pembangkit tenaga listrik. Siklus Kalina KCS34 merupakan siklus yang memanfaatkan campuran ammonia-air sebagai fluida kerja untuk menyerap energi kalor dari sumber panas bertemperatur rendah karena sifat dari campuran ammonia-air yang memiliki titik didih yang rendah. Fraksi campuran ammonia-air dan tekanan kondensor dapat mempengaruhi daya turbin dan efisiensi dari siklus Kalina KCS34. Simulasi optimasi fraksi campuran ammonia-air dan tekanan kondensor dilakukan untuk mengetahui besarnya fraksi campuran ammonia-air dan tekanan kondensor yang sesuai untuk digunakan sebagai pembangkit tenaga listrik di daerah Cimanngu, Provinsi Jawa Barat. Berdasarkan hasil simulasi, untuk mendapatkan kondisi pembangkit yang optimum di lokasi tersebut diperlukan fraksi campuran ammonia-air sebesar 87\% dengan tekanan kondensor 7.6 bar sehingga akan dihasilkan daya turbin sebesar $73.57 \mathrm{~kW}$ dengan efisiensi sistem $14.85 \%$.
\end{abstract}

Kata kunci: Siklus Kalina, optimasi, campuran ammonia-air.

\begin{abstract}
Indonesia have a large potential of geothermal resources. Geothermal resource area such as Cimanggu area, West Java Province has natural hot spring resources. These natural hot spring resource can be utilized for eco tourism and electric power plant. Natural hot spring have relatively low water temperature between $60^{\circ}-90^{\circ} \mathrm{C}$ and it need special technology to be utilized as electric power plant. Kalina cycle KCS34 is a cycle that utilize ammonia-water mixture to absorb energy from low temperature natural hot spring source because of the properties of ammonia-water mixture that can boiled at low temperature. The fraction of ammonia-water mixture and the condensor pressure of the Kalina cycle KCS34 can affect the turbine output power and system efficiency. Optimization simulation was held to discover the required fraction of ammonia-water mixture and condenser pressure that suitable for generating electricity on Cimanggu area, West Java Province. According to the simulation results, the optimum fraction of ammonia-water mixture is $87 \%$ and the condensor pressure at 7.6 bar which will generate 73.57 kW of turbine power with $14.85 \%$ system efficiency.
\end{abstract}

Keywords: Kalina cycle, optimization, ammonia-water mixture. 


\section{PENDAHULUAN}

Indonesia memiliki jalur vulkanik yang terbentang sepanjang Sumatra, Jawa, Bali, hingga Indonesia bagian timur [1]. Potensi panas bumi yang dimiliki Indonesia adalah sekitar 28.617 MW [2]. Potensi panas bumi ini dimanfaatkan untuk pembangkitan listrik, pemandian air panas, dan pariwisata. Pemanfaatan panas bumi sebagai pembangkit listrik yang telah terpasang di Indonesia baru sebesar 1.340 MWe [1].

Sumber air panas di Indonesia umumnya memiliki temperatur sekitar $60-90^{\circ} \mathrm{C}$ dapat dimanfaatkan sebagai pembangkit tenaga listrik [3]. Sumber air panas ini kemudian dimanfaatkan untuk pemandian air panas dimana temperatur airnya sekitar $55^{\circ} \mathrm{C}$ [4]. Perbedaan temperatur tersebut dapat dimanfaatkan untuk pembangkitan tenaga listrik.

Teknologi pembangkit tenaga listrik dengan sumber panas bertemperatur rendah dapat menggunakan siklus Kalina. Siklus Kalina ditemukan oleh Dr. Alexander Kalina dengan memanfaatkan campuran amonia-air sebagai fluida kerja. Campuran amonia-air digunakan sebagai fluida kerja karena memiliki titik didih yang rendah sehingga dengan temperatur sumber panas yang rendah, fluida kerja sudah dapat menguap [4]. Campuran amonia-air akan membentuk campuran non-azeotropik. Pada campuran azeotropik, fasa cair dan uap pada kondisi setimbang memiliki komposisi dan temperatur yang sama sehingga sifatnya sama seperti fluida murni. Pada campuran non-azeotropik, temperatur dan komposisi dari campuran terus berubah selama proses pendidihan. Ketika campuran mulai mendidih, maka akan terbentuk uap dari komponen campuran yang mudah menguap (volatile) [5].

Siklus Kalina sederhana terdiri dari evaporator, separator, turbin, condenser, dan regenerator. Campuran amonia-air akan didihkan di evaporator dengan memanfaatkan panas dari sumber air panas. Kemudian campuran tersebut masuk ke separator kemudian dipisahkan menjadi dua aliran yaitu, aliran dengan konsentrasi amonia dalam bentuk uap yang kemudian diekspansi di turbin dan aliran dengan konsentrasi amonia yang rendah alam fasa cair yang kemudian dilalirkan ke recuperator. Kedua aliran tersebut kemudian menyatu di kondensor dimana campuran tersebut akan dikondensasikan dengan memanfaatkan sumber air dingin. Campuran yang sudah berada dalam fasa cair kemudian dipompa ke regenerator dan siklus akan berulang $[6,7]$.

Pengembangan dari siklus Kalina antara lain KCS (Kalina Cycle System) 11, KCS 34, dan KCS 34g. KCS 11 didesain untuk sumber geotermal dengan temperatur rendah. KCS 34 dan KCS 34g cocok digunakan untuk temperatur sumber panas dibawah $121{ }^{\circ} \mathrm{C}$. Untuk temperatur sumber panas yang rendah tersebut, KCS 34 lebih cocok digunakan untuk aplikasi pemanasan distrik, sedangkan KCS 34g cocok untuk digunakan sebagai pembangkit listrik skala rendah [7]. Pada Gambar 1 diperlihatkan skema dari tipe-tipe siklus Kalina.

Pemanfaatan sumber air panas untuk pembangkit listrik telah dilakukan di Jepang, tepatnya di Matsuyama, prefektur Niigata. Pembangkit listrik ini menggunakan siklus Kalina untuk menghasilkan energi listrik sebesar $50 \mathrm{~kW}$ dan mulai beroperasi sejak 16 Desember 2011 [8].

Pada penelitian ini dilakukan simulasi dari siklus Kalina menggunakan software CYCLE TEMPO 5.0 untuk mendapatkan campuran amonia-air yang optimum dengan variasi tekanan keluaran turbin. Sumber air panas yang disimulasikan pada penelitian ini adalah sumber air panas di Cimanggu, Jawa Barat. 

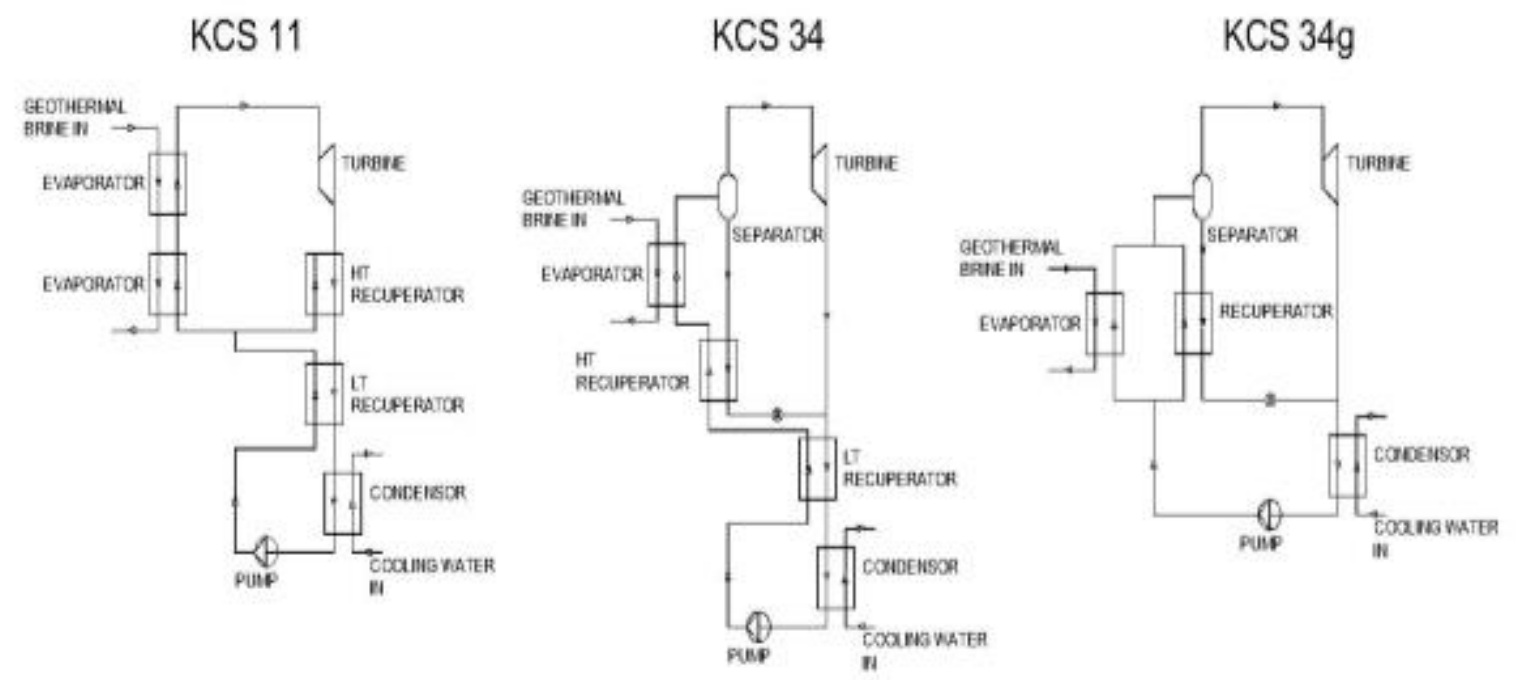

Gambar 1. Sistem Siklus Kalina [7]

\section{METODOLOGI}

\subsection{Deskripsi Siklus}

Siklus Kalina yang digunakan pada penelitian ini adalah siklus Kalina tipe KCS 34 karena berdasarkan penelitan yang telah dilakukan sebelumnya, temperatur air panas di daerah Cimanggu, Jawa Barat berkisar antara $45-80{ }^{\circ} \mathrm{C}$ dan temperatur air dingin sebesar $20{ }^{\circ} \mathrm{C}$ [9]. Komponen pada siklus Kalina KCS 34 terdiri dari evaporator, High temperature recuperator, low temperatur recuperator, kondensor, turbin, dan pompa (Gambar 2).

Skema Gambar 2 mendeskripsikan proses yang terjadi pada sistem KCS34. Pada tahap pertama sistem ini, campuran ammonia-air keluar dari kondensor pada kondisi cair jenuh dengan konsentrasi massa $x_{a m w}$ dan temperatur $T_{1}$ (tingkat keadaan 1). Kemudian campuran ammoni-air dipompakan ke low temperature recuperator (tingkat keadaan 3) dimana campuran ammonia-air dipanaskan awal (preheated) oleh ammonia konsentrasi tinggi yang keluar dari turbin (tingkat keadaan 9) dan campuran ammonia-air konsentrasi rendah dari high temperature recuperator (tingkat keadaan 15).Campuran ammonia-air yang telah dipanaskan kemudian dialirkan ke high temperature recuperator (tingkat keadaan 2) untuk dinaikkan temperaturnya. Kemudian campuran ammonia-air (tingkat keadaan 4) tersebut dididihkan di evaporator oleh sumber air panas dengan temperatur $T_{11}$. Temperatur operasi evaporator $T_{8}$ yang berada antara temperatur didih dan temperatur embun akan menghasilkan campuran dua fasa yaitu fasa cair dengan konsentrasi ammonia rendah dan fasa uap dengan konsentrasi ammonia tinggi (tingkat keadaan 8). Campuran dua fasa ini kemudian dipisahkan di separator. Campuran dengan konsentrasi ammonia rendah kemudian dialirkan ke high temperatur recuperator (tingkat keadaan 7 ) untuk memanaskan campuran ammonia-air, sedangkan ammonia dengan konsentrasi tinggi (tingkat keadaan 13) dialirkan ke turbin pada tekanan $P_{13}$. Energi dari ammonia konsentrasi tinggi tersebut kemudian diekstrak oleh turbin menjadi kerja. Ammonia konsentrasi tinggi dari turbin kemudian dialirkan ke low temperatur recuperator (tingkat keadaan 9) dan bercampur dengan campuran ammonia konsentrasi rendah (tingkat keadaan 15). Campuran ammonia-air yang telah didinginkan di low temperatur recuperator kemudian dikondensasikan (tingkat keadaan 10) di condensor dengan memanfaatkan sumber air dingin (tingkat keadaan 5) dengan temperatur $T_{5}$. 


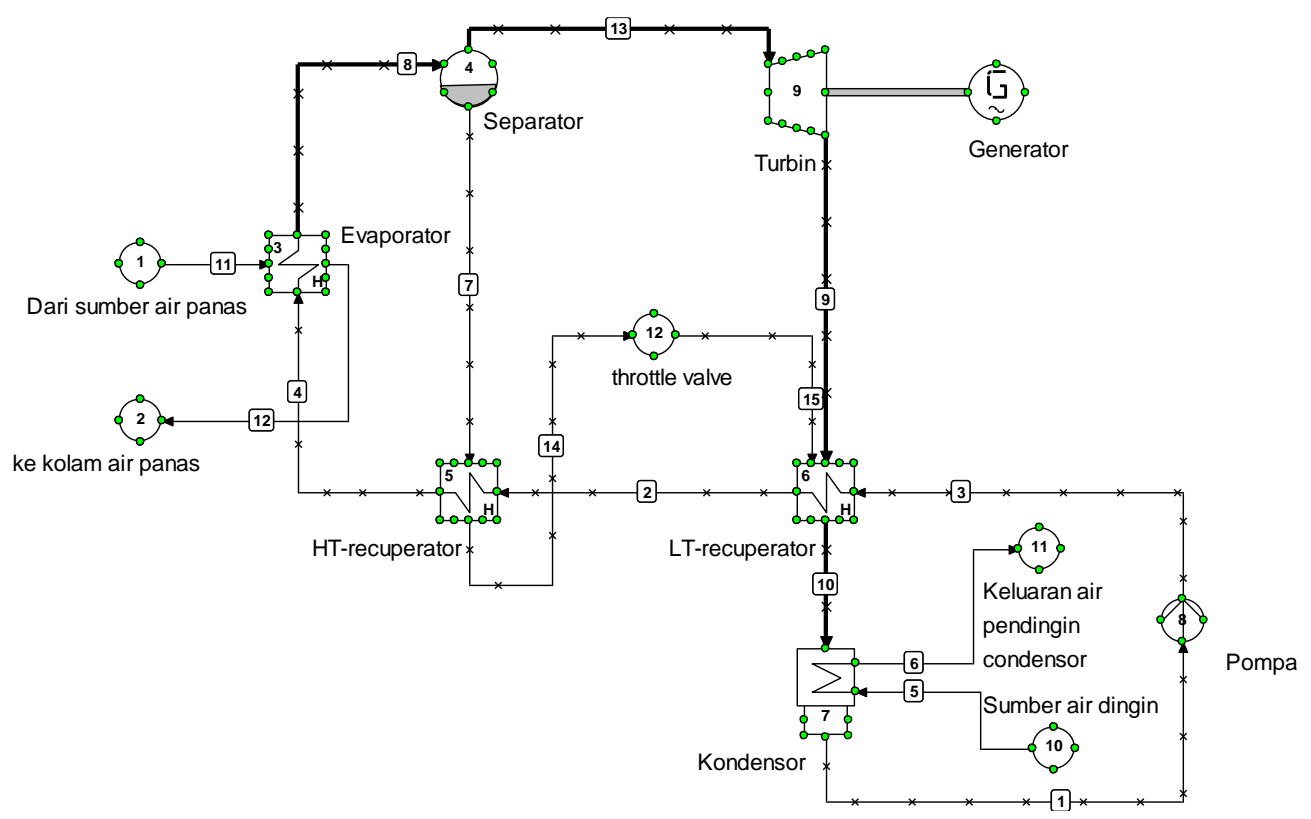

Gambar 2. Skema simulasi siklus Kalina KCS34

\subsection{Metodologi Penelitian}

Pada penelitian ini dilakukan pengukuran temperatur di lokasi sumber air panas di Cimanggu, Jawa Barat sebagai data primer untuk melakukan simulasi. Data-data lain dari literatur juga digunakan sebagai pembanding. Data-data tersebut kemudian diolah untuk digunakan sebagai parameter dalam melakukan simulasi menggunakan software CYCLE TEMPO 5.0. Hasil simulasi kemudian dianalisis untuk mengetahui kondisi optimum dari siklus Kalina KCS 34. Diagram alir dari penelitian ini dapat dilihat pada Gambar 3.

Proses simulasi dilakukan dengan memvariasikan campuran ammonia-air dan tekanan kondensor untuk mendapatkan kondisi optimum dari siklus KCS34 untuk lokasi tersebut. Hasil dari simulasi kemudian dianalisis dan selanjutnya ditarik kesimpulan dari penelitian yang telah dilakukan.

\subsection{Analisis Sistem}

Sifat termodinamika dari campuran ammonia-air dapat dihitung menggunakan metode energi bebas Gibbs. Kondisi setimbang dari campuran ammonia-air diperoleh dengan memperhitungkan potensi kimia dari setiap fasa untuk setiap elemen [10].

$$
\begin{aligned}
& \mu_{a}^{L}=\left(\frac{\partial G_{m}^{L}}{\partial N_{a}}\right)_{T, P, N_{w}}=\left(\frac{\partial G_{m}^{\varepsilon}}{\partial N_{a}}\right)_{T, P, N_{w}}=\mu_{a}^{\varepsilon} \\
& \mu_{w}^{L}=\left(\frac{\partial G_{m}^{L}}{\partial N_{w}}\right)_{T, P, N_{a}}=\left(\frac{\partial G_{m}^{\varepsilon}}{\partial N_{w}}\right)_{T, P, N_{a}}=\mu_{w}^{\varepsilon}
\end{aligned}
$$

Dimana $N_{a}$ dan $N_{w}$ merupakan jumlah mol dari ammonia dan air. Persamaan energi bebas Gibbs $G_{m}$ untuk fasa cair dan gas dituliskan sebagai berikut [10]: 


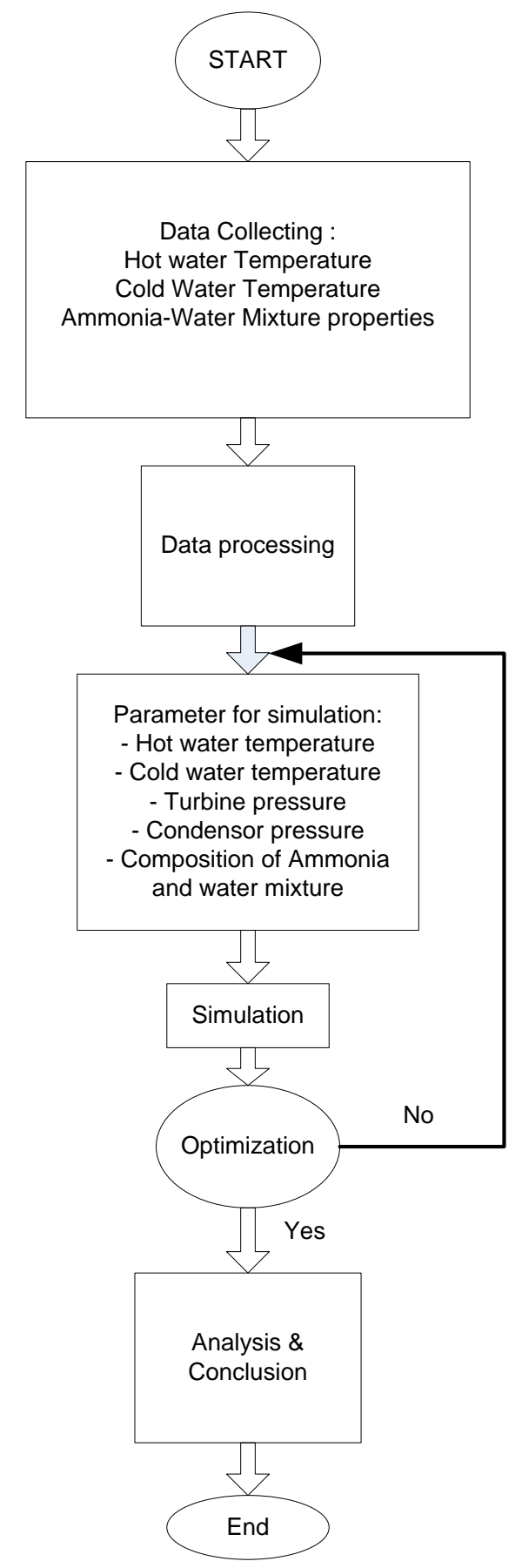

Gambar 3. Diagram alir penelitian

$$
G_{m}=N_{a}\left[G_{a}+R T \ln x\right]+N_{w}\left[G_{w}+R T \ln (1-x)\right]+N G^{E}
$$

Pada skema siklus Kalina KCS34 (Gambar 2), energi kalor dari sumber air panas diserap oleh campuran ammonia air pada evaporator. Dengan asumsi tidak adanya kerugian panas dari sistem ke lingkungan, maka energi kalor yang diserap oleh campuran ammonia air dapat dihitung dengan:

$$
Q_{3}=m_{11}\left(h_{11}-h_{12}\right)
$$

Dimana $h$ menunjukkan enthalpi spesifik dan $m$ merupakan laju aliran massa. Kerja netto yang dihasilkan oleh sistem merupakan selisih dari kerja yang dihasilkan oleh turbin $\left(W_{t}\right)$ dengan kerja yang dibutuhkan oleh pompa $\left(W_{p}\right)$. Kerja netto $W_{\text {net }}$ dijabarkan dalam persamaan: 


$$
W_{\text {nett }}=W_{t}-W_{p}=m_{13}\left(h_{13}-h_{9}\right)-m_{1}\left(h_{3}-h_{1}\right)
$$

Efisiensi termal dari sistem menunjukkan besarnya energi kalor yang diserap oleh campuran ammonia-air yang dapat diubah menjadi kerja netto. Efisiensi termal sistem dapat dihitung dengan menggunakan persamaan:

$$
\eta_{n e t t}=W_{t}-W_{p} / Q_{3}
$$

\subsection{Simulasi dan Optimalisasi}

Simulasi model Kalina Cycle System (KCS) 34 dilakukan menggunakan program Cycle Tempo 5.0 seperti pada Gambar 2, dengan input data dari pengolahan data hasil pengukuran langsung dan data sekunder. Kondisi optimum dari sistem ditunjukkan dengan daya maksimum yang dihasilkan turbin dengan dua tahap simulasi, yaitu:

a. pertama, simulasi dilakukan untuk mendapatkan kisaran komposisi campuran ammonia-air yang optimum tanpa melanggar kesetimbangan massa dan energy,

b. langkah kedua adalah dengan memvariasikan tekanan kondensor untuk mendapatkan daya maksimum dari komposisi ammonia-air yang telah disimulasikan.

\section{HASIL DAN PEMBAHASAN}

Temperatur sumber air panas di lokasi pengukuran berkisar antara $60-80^{\circ} \mathrm{C}$, sedangkan temperatur air dingin berkisar antara $18-22^{\circ} \mathrm{C}$. Pada simulasi ini akan digunakan temperatur air panas maksimum $80^{\circ} \mathrm{C}$ dan temperatur air dingin rata-rata $20^{\circ} \mathrm{C}$ [9].

Simulasi dilakukan dengan menggunakan tekanan masuk turbin sebesar 10 bar dan temperatur campuran amonia-air $77{ }^{\circ} \mathrm{C}$ [9]. Pada simulasi ini divariasikan pula komposisi dari campuran ammonia-air dan tekanan kondensor untuk mendapatkan hasil yang optimum. Parameter yang digunakan untuk simulasi dapat dilihat pada Tabel 1. Pada simulasi ini diasumsikan kerugian tekanan antara turbin dan kondensor, kerugian panas dari sistem ke lingkungan, dan kerugian energi pada pipa diabaikan

Tabel 1. Parameter untuk simulasi

\begin{tabular}{llll}
\hline Apparatus & Parameter & Unit & Value \\
\hline Pump & $\mathrm{P}_{\text {out }}$ & bar & 12 \\
LT-recuperator & $\mathrm{T}_{\text {out }}$ & ${ }^{\circ} \mathrm{C}$ & 35 \\
HT-recuperator & $\mathrm{T}_{\text {out }}$ & ${ }^{\circ} \mathrm{C}$ & 40 \\
Evaporator & $\mathrm{T}_{\text {out }}$ & ${ }^{\circ} \mathrm{C}$ & 77 \\
Turbine & $\mathrm{P}_{\text {in }}$ & bar & 10 \\
Tekanan kondensor & $\mathrm{P}_{\text {in }}$ & bar & $7-8.4$ \\
\hline
\end{tabular}

\subsection{Optimasi Campuran Ammonia-Air}

Simulasi optimasi dari campuran ammonia-air akan dilakukan pada tingkat keadaan stedi dengan parameter-parameter yang telah ditetapkan. Pada tahap awal tekanan kondensor ditentukan terlebih dahulu kemudian dilakukan pemilihan komposisi campuran ammonia-air dengan metode grafis menggunakan grafik tekanan vs temperatur campuran ammonia-air berdasarkan Gambar 4 . 

Pembangkit Listrik

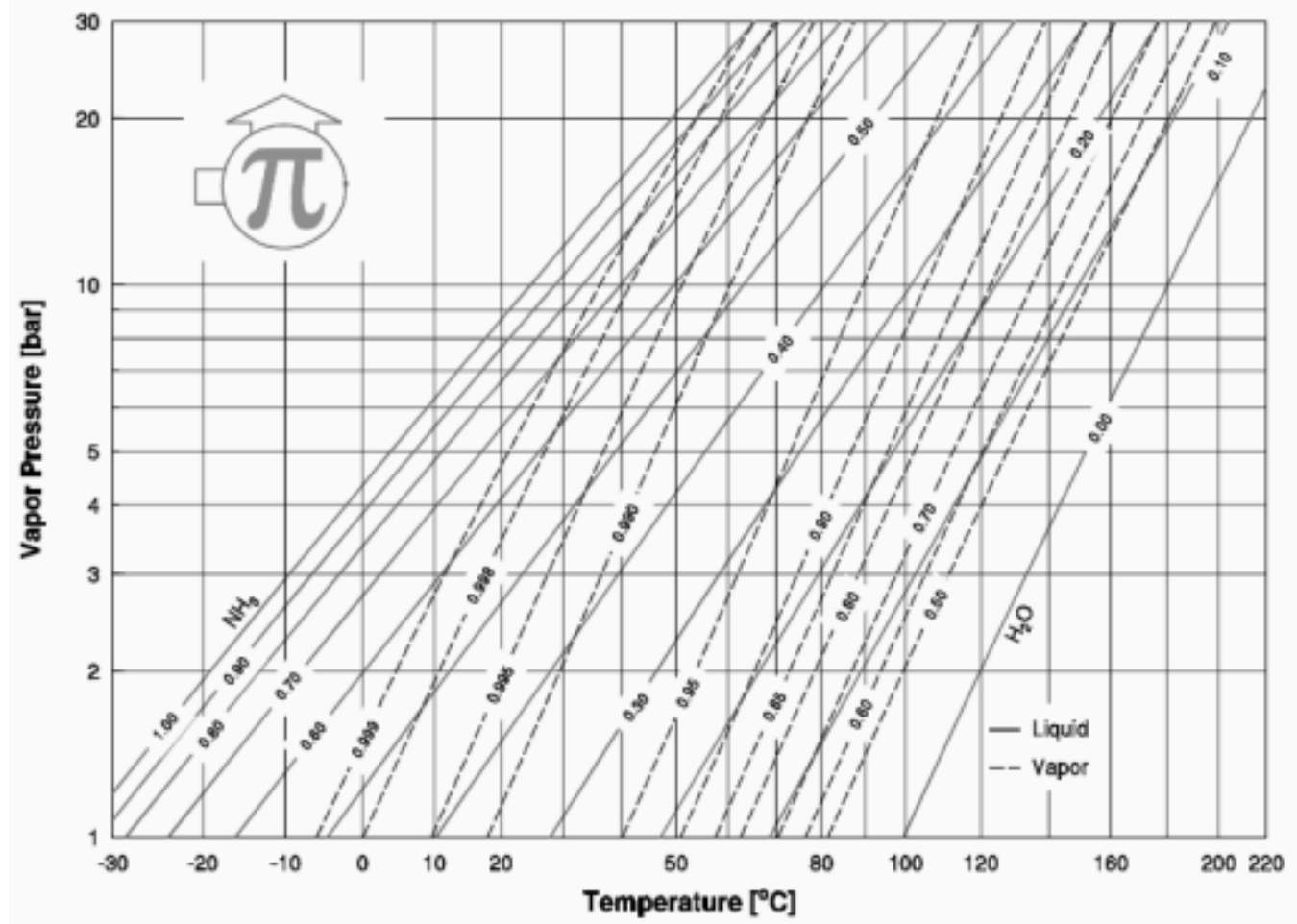

Gambar 4. Grafik temperatur vs tekanan pada campuran ammonia-air [11]

Agar campuran ammonia dan air dapat terkondensasi pada temperatur air dingin $22{ }^{\circ} \mathrm{C}$, dan dapat terevaporasi pada temperatur $77^{\circ} \mathrm{C}$, maka dari Gambar 4 diperoleh fraksi campuran ammonia-air sebesar $80 \%$. Kemudian dari data tersebut dilakukan simulasi menggunakan cycle tempo seperti yang disajikan pada Gambar 5.

Fraksi campuran ammonia-air divariasikan sehingga tidak melanggar kesetimbangan massa dan energi berkisar. Dari hasil simulasi diperoleh fraksi campuran ammonia-air antara 75\% hingga 89\%. Berdasarkan hasil simulasi, daya yang dihasilkan cenderung menurun seiring dengan peningkatan tekanan kondensor dan fraksi campuran ammonia-air seperti terlihat pada Gambar 6. Hal ini disebabkan adanya kenaikan enthalpi di sisi masuk kondensor sehingga akan mengurangi daya yang dihasilkan turbin.

Efisiensi sistem berdasarkan hasil simulasi memiliki kecenderungan meningkat seiring dengan peningkatan fraksi campuran ammonia-air seperti ditunjukkan pada Gambar 6 (b). Semakin besar fraksi campuran ammonia-air, maka temperatur kondensasi campuran akan menurun sehingga enthalpi campuran keluar dari kondensor akan meningkat. Kondisi tersebut akan membuat daya yang diperlukan pompa menurun dan energi yang diperlukan untuk menguapkan campuran akan berkurang. Pada fraksi campuran yang konstan, efisiensi sistem cenderung menurun seiring dengan kenaikan tekanan. Hal ini disebabkan oleh penurunan enthalpi pada sisi masuk kondensor sehingga daya turbin menurun. 


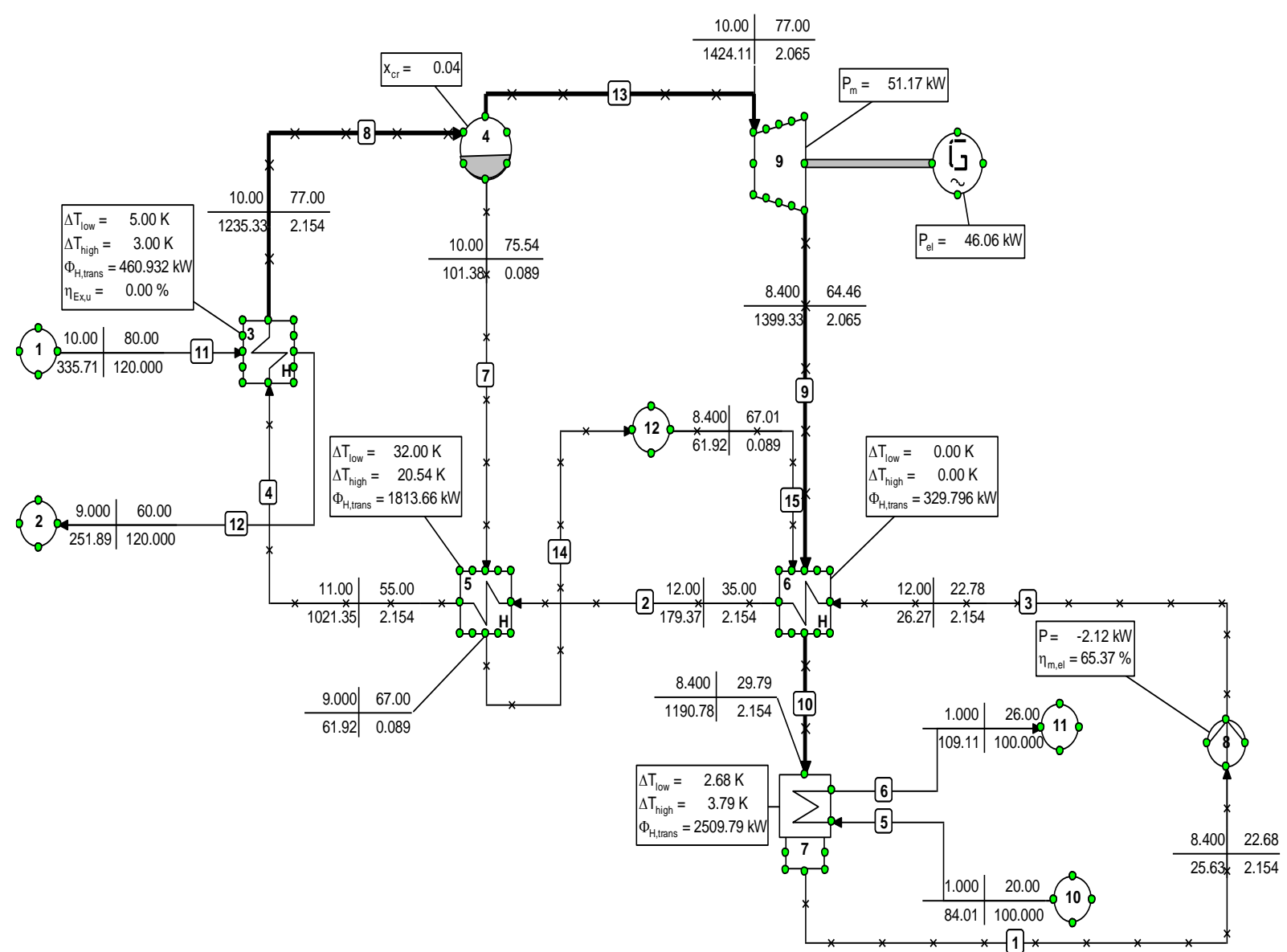

Gambar 5. Hasil simulasi menggunakan Cycle Tempo pada komposisi campuran $89 \%$ dan tekanan kondensor 8.4 bar

Berdasarkan hasil simulasi dengan memvariasikan tekanan kondensor dan fraksi campuran ammoniaair, diperoleh efisiensi sistem tertinggi sebesar $14.85 \%$ pada tekanan kondensor 7.6 bar dan fraksi campuran ammonia-air sebesar 87\% seperti terlihat pada Gambar 6 (c). Efisiensi dari sistem tergolong kecil karena sumber panas yang tersedia memiliki temperatur yang rendah sehingga laju aliran campuran ammonia-air yang diperlukan untuk proses evaporasi juga rendah. Rekapitulasi hasil simulasi dapat dilihat pada Tabel 2.

Tabel 2. Hasil Simulasi

\begin{tabular}{c|c|c|c}
\hline $\begin{array}{c}\text { Condensor } \\
\text { pressure } \\
\text { (bar) }\end{array}$ & $\begin{array}{c}\text { Mixture } \\
\text { fraction }\end{array}$ & $\begin{array}{c}\text { Turbine } \\
\text { Output } \\
\text { Power } \\
\text { (kW) }\end{array}$ & $\begin{array}{c}\text { System } \\
\text { Efficiency }\end{array}$ \\
\hline 7 & $80 \%$ & 91.43 & $12.90 \%$ \\
\hline 7.2 & $82 \%$ & 85.38 & $13.31 \%$ \\
\hline 7.4 & $85 \%$ & 79.76 & $14.48 \%$ \\
\hline 7.6 & $87 \%$ & 73.57 & $14.85 \%$ \\
\hline 7.8 & $88 \%$ & 67.01 & $14.28 \%$ \\
\hline 8 & $89 \%$ & 65.49 & $13.64 \%$ \\
\hline 8.2 & $89 \%$ & 58.24 & $12.12 \%$ \\
\hline 8.4 & $89 \%$ & 51.17 & $10.64 \%$ \\
\hline
\end{tabular}




\section{SIMPULAN}

Dengan menggunakan Cycle Tempo 5.0 simulasi optimasi sistem Kalina KCS34 untuk pemanfaatan sumber air panas sebagai pembangkit listrik dapat dilakukan. Temperatur sumber air panas yang rendah dapat digunakan sebagai media pemanas untuk mengevaporasi campuran ammonia-air. Lokasi sumber air panas di Cimanggu, Provinsi Jawa Barat memiliki potensi untuk dikembangkan menjadi pembangkit tenaga listrik yang bersih. Berdasarkan hasil simulasi, untuk mendapatkan kondisi pembangkit yang optimum di lokasi tersebut diperlukan fraksi campuran ammonia-air sebesar 87\% dengan tekanan kondensor 7.6 bar sehingga akan dihasilkan daya turbin sebesar $73.57 \mathrm{~kW}$ dengan efisiensi sistem $14.85 \%$.

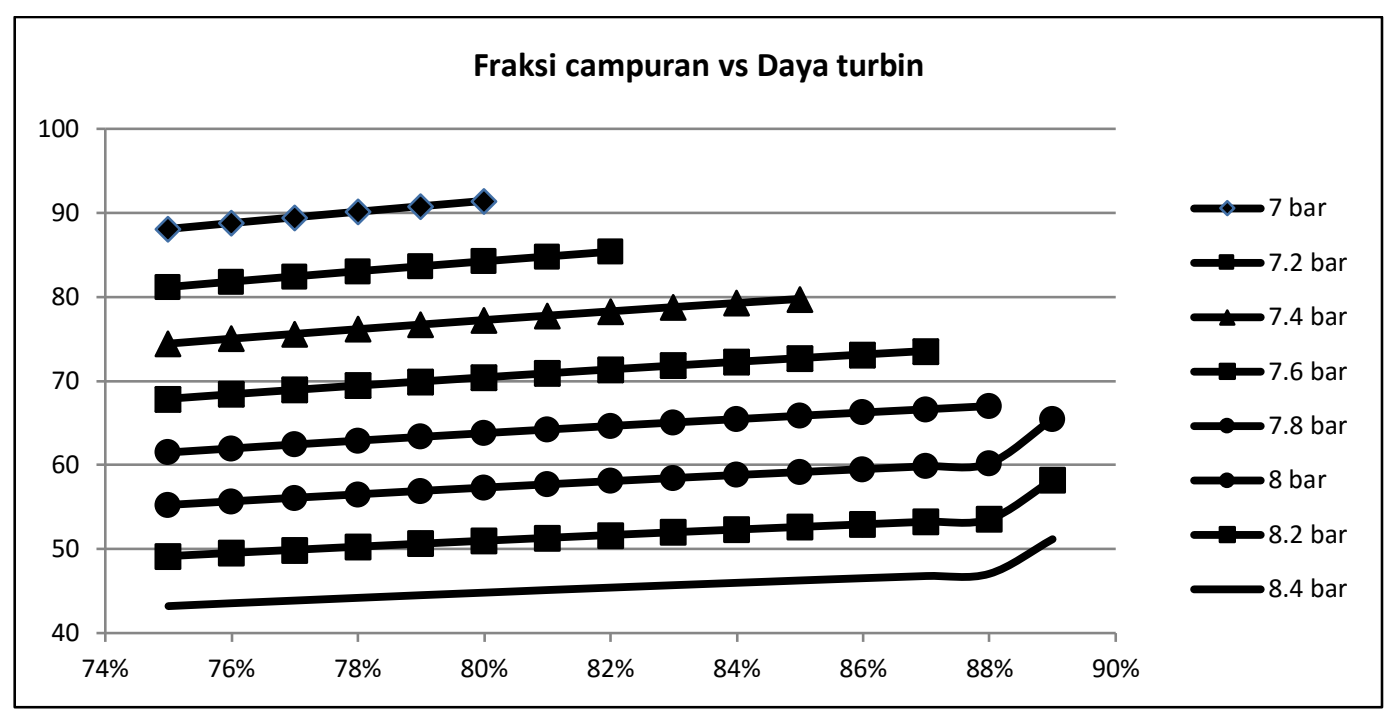

(a) Grafik fraksi campuran terhadap daya turbin

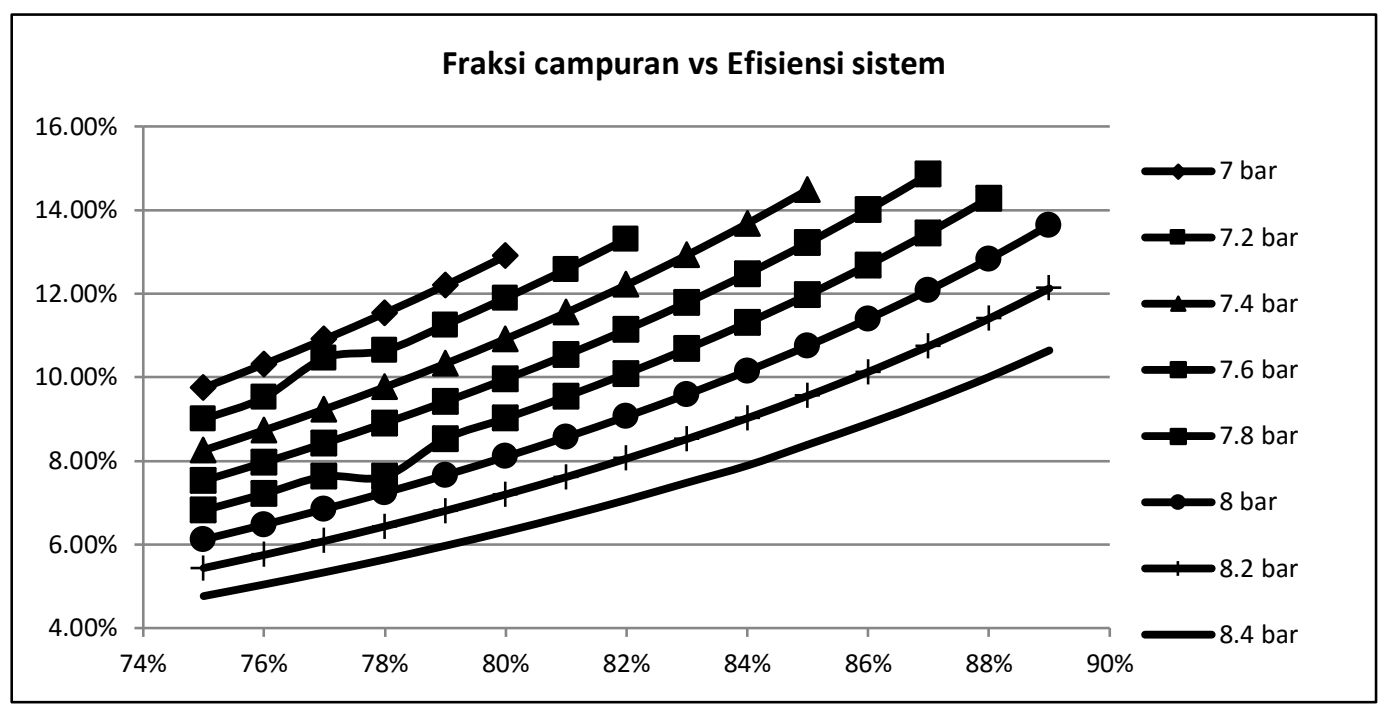

(b) Grafik fraksi campuran terhadap efisiensi sistem 


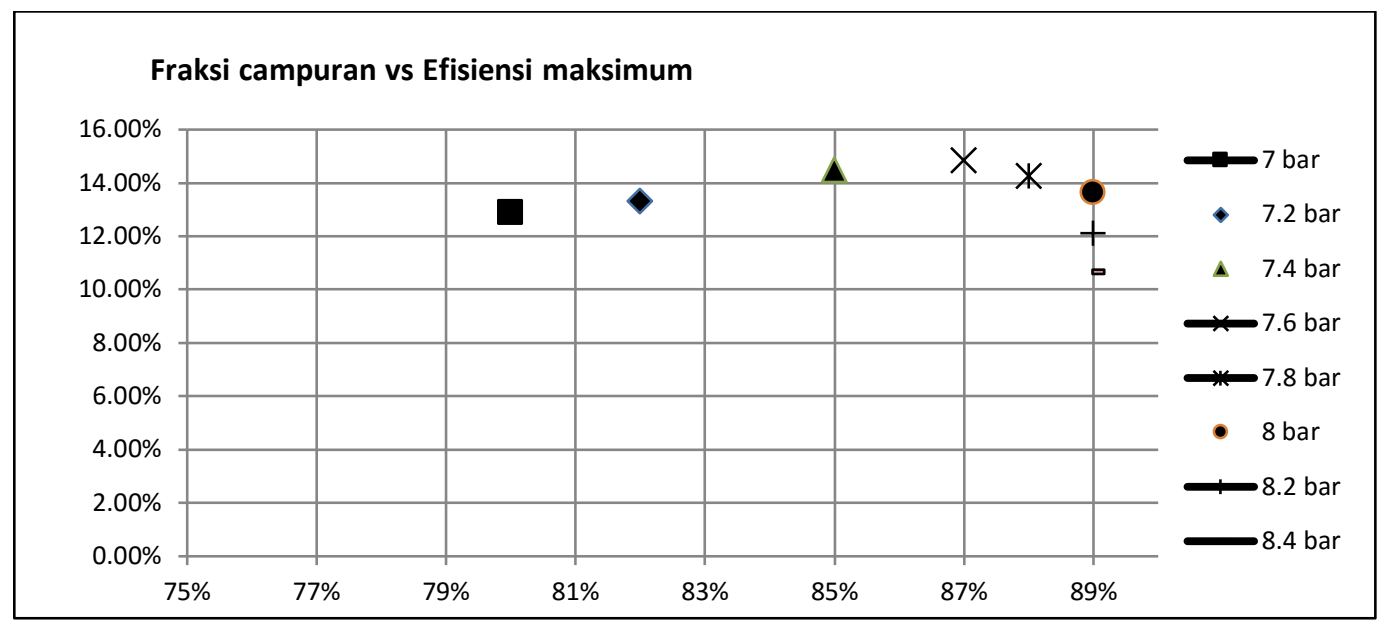

(c) Grafik fraksi campuran terhadap efisiensi maksimum pada tiap tekanan

Gambar 6. Grafik hasil simulasi Cycle Tempo

\section{DAFTAR PUSTAKA}

[1] Bertani. R, (2015). Geothermal Power Generation in the World 2010-2014 Update Report, Proceeding World Geothermal Congress 2015. Melbourne, Australia., pp 1-19.

[2] Badan Pengkajian dan Penerapan Teknologi (BPPT), (2014). INDONESIA ENERGY OUTLOOK 2014 : Pengembangan Energi untuk Mendukung Program Substitusi BBM. http:// www.bppt.go.id.

[3] Pikra. G, (2014). Pengaruh Temperatur Fluida Pendingin pada Kinerja Pembangkit Listrik Rankine Organik dari Sumber Kalor Mata Air Panas Cimanggu, Ciwidey. Prosiding Seminar Nasional Fisika 2014,ISSN 2088-4176

[4] Hashizume. T, (2004). Power Generation Technology by Hot Water Heating of Low Temperature Power Generation Using Ammonia and Ammonia-Water Mixture as Working Fluid. Proceeding of the $6^{\text {th }}$ Asian Geothermal Symposium: Mutual Challenge in High-and Low-Temperature Geothermal Resource Fields. Korea., pp 5-7.

[5] Jonsson. M, (2003). Advanced Power Cycles With Mixtures as the Working Fluid. Doctoral Thesis, Departement of Chemical Engineering and Technology, Energy Processes, Royal Institute of Technology. ISBN 91-7283-443-9, Stockholm, Sweden.

[6] Köhler. S and Saadat. A, (2003). Thermodynamic Modelling of Binary Cycles Looking for Best Case Scenarios, International Geothermal Converence 2003. Reykjavik, Iceland., pp14-19.

[7] Mlcak. H. A, (2002). Kalina Cycle ${ }^{\circledR}$ Concepts for Low Temperature Geothermal, Geothermal Recources Council Transactions. Vol.26, pp 707-711

[8] Yangisawa. N. et al, (2012). Starting Field Test of Kalina System Using Hot Spring in Japan. GHC Bulletin, February 2012. Oregon, U.S.A.

[9] M. Pramuda N. S. et al, (2015). Studi Potensi Pemanfaatan Sumber Air Panas (Natural Hot Spring) Sebagai Pembangkit Listrik. Prosiding Seminar Nasional XIV Rekayasa dan Aplikasi Teknik Mesin di Industri, ISBN 978-602-74127-0-5, Bandung, Indonesia. pp. TKE 66-TKE 71.

[10] Kim. K. H. et al, (2013). Performance Asessment of Ammonia-Water Based Power and Refrigeration Cogeneration Cycle. International Journal of Materials, Mechanics and Manufacturing, Vol. 1, No.1, February 2013, pp 36-40.

[11] M. Conde Engineering, (2004). Thermophysical Properties of $\left\{\mathrm{NH}_{3}+\mathrm{H}_{2} \mathrm{O}\right\}$ Solutions for the Industrial Design of Absorption Refrigeration Equipment. M. Conde Engineering, Zurich. 